05

\title{
Влияние содержания кобальта на прочностные свойства керамики на основе карбида вольфрама при динамических нагрузках
}

\author{
(C) A.C. СавиныX, ${ }^{1,2}$ K. Mandel, ${ }^{3}$ C.B. Разоренов, ${ }^{1,2}$ L. Krüger ${ }^{3}$ \\ ${ }^{1}$ Институт проблем химической фризики РАН, \\ 142432 Черноголовка, Россия \\ ${ }^{2}$ Национальный исследовательский Томский государственный университет, \\ 634050 Томск, Россия \\ ${ }^{3}$ Технический университет „Фрайбергская горная академия“, \\ 09599 Фрайберг, Германия \\ e-mail: savas@ficp.ac.ru
}

(Поступило в Редакцию 27 марта 2017 г. В окончательной редакции 18 сентября 2017 г.)

На основе регистрации и анализа полных волновых профилей проведены измерения динамического предела упругости и откольной прочности керамики на основе карбида вольфрама с различным содержанием кобальта. Исследовано также влияние концентрации кобальта на механические характеристики карбида вольфрама, такие как твердость, трещиностойкость, модуль Юнга, модуль сдвига, скорость звука. Показано, что разрушающие напряжения при отколе увеличиваются, а динамический предел упругости уменьшается практически линейно в рамках разброса их значений с ростом концентрации кобальта, причем величина предела упругости уменьшается скачком практически в 2 раза при увеличении концентрации кобальта от 0 до $2 \%$.

DOI: 10.21883/JTF.2018.03.45592.2267

\section{Введение}

Керамика на основе карбида вольфрама широко применяется в различных областях промышленности, включая оборонную отрасль, благодаря ее высокой плотности, твердости, высокой температуре плавления, низкого коэффициента трения, химической стойкости и стойкости к окислению. Изделия из керамики карбида вольфрама могут быть использованы, например, в качестве тяжелых сердечников в снарядах, а в машиностроении - как режущий инструмент. Также карбид вольфрама используется как важный компонент в экспериментах с высоким давлением в алмазных наковальнях. Для увеличения пластичности и прочности при изготовлении керамики карбида вольфрама в нее добавляют различные металлы, в частности кобальт. Существуют различные методы получения керамики карбида вольфрама - спекание под высоким давлением, взрывное компактирование [1], а также развивающийся в последнее время метод плазменного искрового спекания.

Применение керамики на основе карбида вольфрама в изделиях, работающих при динамических нагрузках, требует изучения его свойств, в частности, сжимаемости и прочности, при интенсивных импульсных воздействиях. Анализ литературы по исследованию поведения карбида вольфрама, изготовленного горячим прессованием при ударном сжатии, показал следующее. Измерения ударной адиабаты Гюгонио были выполнены в диапазоне давлений от 18 до $200 \mathrm{GPa}$ [2] и от 33 до $516 \mathrm{GPa}$ [3]. В работе [4] такие измерения сделаны в диапазоне от 5 до $60 \mathrm{GPa}$ для нескольких видов керамики карбида вольфрама. В этой же работе проводилось нагруже- ние образцов плоскими и сферическими волнами для определения характера разрушения и фрагментации керамических образцов, и были определены динамический предел упругости, равный $4.1 \mathrm{GPa}$, и откольная прочность, величина которой варьировала в пределах 2.7-3.6 GPa. В работе [5] была проведена серия ударноволновых экспериментов с карбидом вольфрама, содержащего 8.5\% кобальта, что позволило определить величину его откольной прочности, равной $4.38 \mathrm{GPa}$, и динамического предела упругости, равного $3.3 \pm 0.2 \mathrm{GPa}$. В работе [6] был измерен динамический предел упругости горячепрессованного карбида вольфрама, который оказался равным $6.6 \pm 0.5 \mathrm{GPa}$. В работе [7] определено уравнение состояния горячепрессованных керамик WC и $\mathrm{WC}-6 \% \mathrm{Co}$ при нагружении до $50 \mathrm{GPa}$ в статических условиях с использованием алмазных наковален. В работе [8] проведено исследование керамики оксида алюминия, полученной методом плазменно-искрового спекания при ударно-волновом нагружении. Показано, что ее динамический предел упругости затухает с $21 \mathrm{GPa}$ у образца толщиной $0.28 \mathrm{~mm}$ до $12 \mathrm{GPa}$ у образца толщиной $6 \mathrm{~mm}$, что является максимальным значением из измеренных для этих керамик, полученных методом горячего прессования. Данных об упругопластических и прочностных свойствах керамики карбида вольфрама, полученного методом плазменно-искрового спекания, в литературе практически нет. С целью восполнения этого пробела в настоящей работе были выполнены измерения прочностных характеристик керамики на основе карбида вольфрама с различным содержанием кобальта при статических условиях и при ударно-волновом нагружении. 


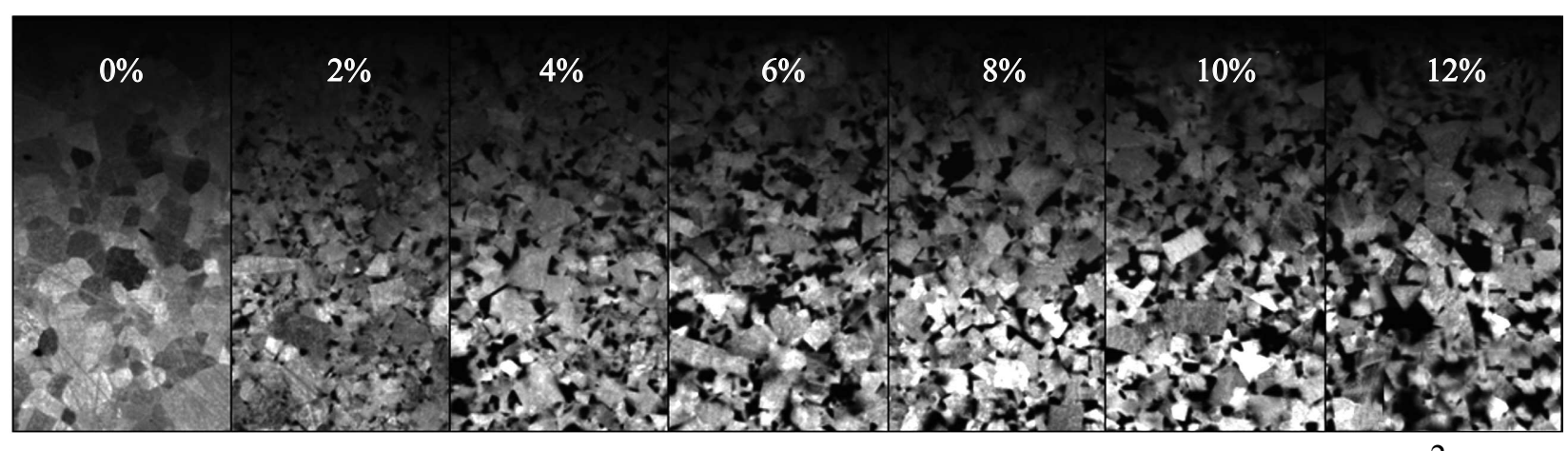

$2 \mu \mathrm{m}$

Рис. 1. Фотографии микроструктуры образцов карбида вольфрама с различным содержанием кобальта.

\section{Исследованные образцы}

Беспористые образцы чистого карбида вольфрама были изготовлены путем спекания чистого порошка карбида вольфрама марки DN-4 (H.C. Starck, Germany) методом плазменно-искрового спекания (в англоязычный литературе обозначаемый как SPS - Spark Plasma Sintering [9]) при температуре $1800^{\circ} \mathrm{C}$ в течение $3 \mathrm{~min}$. По сравнению с традиционными методами метод SPS позволяет получать высококачественные спеченные материалы при меньших температурах и за меньшее время. Керамические образцы карбида вольфрама с различным содержанием кобальта изготавливались следующим образом. Порошок карбида вольфрама марки DN-4 смешивался с разным количеством (от 2 до 12\%) порошкового кобальта со средним размером частиц $\sim 0.5 \mu \mathrm{m}$ (Umicore, Belgium) в планетарной шаровой мельнице в течение $500 \mathrm{~min}$ [10]. Готовая смесь спекалась методом плазменно-искрового спекания при температуре $1250^{\circ} \mathrm{C}$ в течение $5 \mathrm{~min}$ [11]. Все изготовленные таким методом образцы имели диаметр $20 \mathrm{~mm}$ и толщину около $5 \mathrm{~mm}$. Далее образцы подвергались шлифованию.

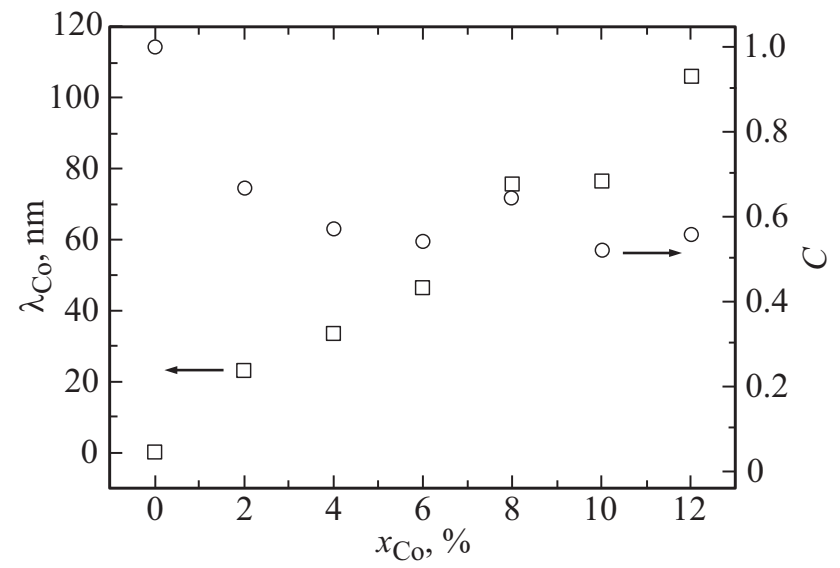

Рис. 2. Средняя толщина прослойки свободного кобальта $\lambda_{\text {со }}$ и количество связанного кобальта $C$ в зависимости от его концентрации в исследуемых образцах.
Параметры микроструктуры исследуемых образцов карбида вольфрама с различной концентрацией кобальта были определены из анализа их микрофотографий, полученных с помощью сканирующего электронного микроскопа (SEM) Carl Zeiss LEO 1530. Перед микроскопическими исследованиями поверхность образцов обрабатывалась щелочным водным раствором ферроцианида калия $\left(\mathrm{K}_{3}\left[\mathrm{Fe}(\mathrm{CN})_{6}\right] / \mathrm{KOH}\right)$, после чего на нее напылялся тонкий слой углерода. SEM микрофотографии структуры исследуемых образцов с различным содержанием кобальта представлены на рис. 1. Обработка изображений осуществлялась с помощью компьютерной программы „Aquinto a4i-Analysis“ Для определения размера зерен карбида вольфрама $d_{\mathrm{WC}}$ было использовано логарифмическое распределение для всех измеренных зерен. Толщину прослойки свободного кобальта между зернами карбида вольфра-

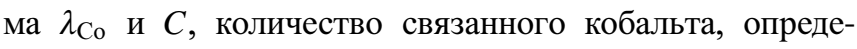
ляли из уравнений $\lambda_{\mathrm{Co}}=d_{\mathrm{WC}} \cdot \varphi_{\mathrm{Co}} /\left((1-C) \cdot\left(1-\varphi_{\mathrm{Co}}\right)\right)$ и $C=\left(N_{\mathrm{WC}}-N_{\mathrm{Co}}\right) / N_{\mathrm{WC}}$ соответственно. Здесь $\varphi_{\mathrm{Co}}-$ объем фракции кобальта, рассчитанный из начального веса порошка, а $N$ - число зерен каждой фазы.

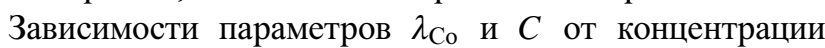
кобальта показаны на рис. 2. Видно, что параметр $\lambda_{\text {Со }}$ находится в диапазоне от 0 (при отсутствии кобальта в составе образца) до $\sim 100 \mathrm{~nm}$, возрастая с увеличением концентрации кобальта в образцах. При отсутствии в образцах кобальта величина $C$, как это следует из формулы, равна единице. С ростом концентрации кобальта в образцах ее величина варьируется в пределах от 0.52 до 0.67 без заметного влияния содержания кобальта. Это означает, что распределение кобальта вокруг зерен карбида вольфрама одинаковое при различной концентрации кобальта в образцах.

\section{Механические характеристики керамики карбида вольфрама}

Продольная и сдвиговая скорости звука, модуль сдвига и модуль Юнга, а также коэффициент Пуассона 
Таблица 1. Механические свойства керамики карбида вольфрама с различным содержанием кобальта. Здесь $\rho_{0}-$ измеренная плотность образцов, $\rho_{\text {rel }}-$ отношение измеренной плотности к теоретической, $c_{s}-$ сдвиговая скорость звука, $c_{l}-$ продольная скорость звука, $v$ - коэффициент Пуассона, $E, G$ - модуль Юнга и модуль сдвига, $d_{\mathrm{wc}}-$ средний размер зерна.

\begin{tabular}{c|c|c|c|c|c|c|c|c|c|c}
\hline № & $x_{\mathrm{Co}}, \%$ & $h_{\text {samp }}, \mathrm{mm}$ & $\rho_{0}, \mathrm{~g} / \mathrm{cm}^{3}$ & $\rho_{\text {rel }}, \%$ & $c_{s}, \mathrm{~m} / \mathrm{s}$ & $c_{l}, \mathrm{~m} / \mathrm{s}$ & $v$ & $E, \mathrm{GPa}$ & $G, \mathrm{GPa}$ & $d_{\mathrm{WC}, \mathrm{nm}}$ \\
\hline WC & 0 & 3.99 & 15.66 & 99.9 & 4384 & 7164 & 0.201 & 723 & 301 & 330 \\
WC-2Co & 2 & 3.80 & 15.1 & 97.9 & 4256 & 7012 & 0.208 & 670 & 277 & 213 \\
WC-4Co & 4 & 3.79 & 14.94 & 98.3 & 4233 & 6993 & 0.210 & 656 & 271 & 195 \\
WC-6Co & 6 & 3.98 & 14.95 & 99.9 & 4177 & 6896 & 0.210 & 631 & 261 & 188 \\
WC-8Co & 8 & 3.78 & 14.58 & 98.9 & 4124 & 6891 & 0.221 & 608 & 249 & 183 \\
WC-10Co & 10 & 3.80 & 14.53 & 100 & 4061 & 6815 & 0.224 & 585 & 239 & 186 \\
WC-12Co & 12 & 3.98 & 14.27 & 99.8 & 4010 & 6722 & 0.223 & 565 & 231 & 195
\end{tabular}

были определены с помощью так называемого метода ультразвукового прозвучивания при частоте $5 \mathrm{MHz}$ с использованием ультразвуковой приставки Модели 5800 и осциллографа Hitachi V-1565.

Для определения твердости и трещиностойкости полученных образцов последние разрезались на две половины, плоскость одной шлифовалась и полирова-

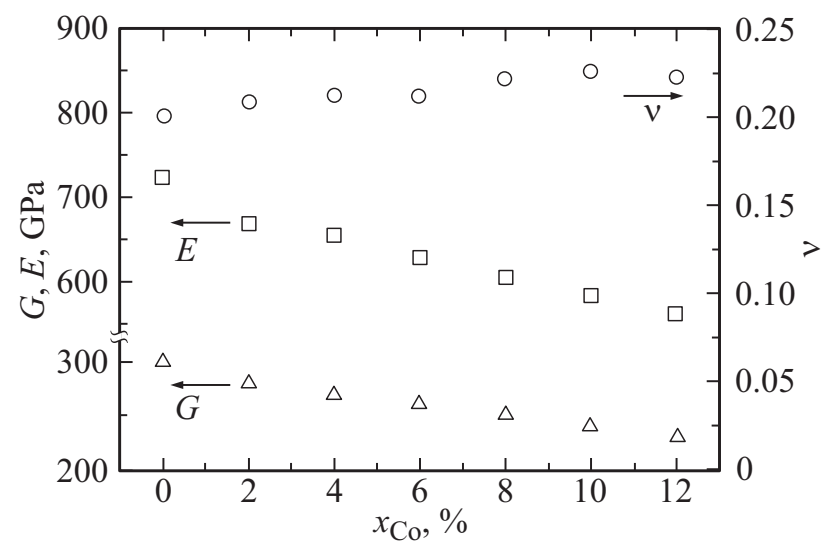

Рис. 3. Зависимости модуля сдвига, модуля Юнга и коэффициента Пуассона карбида вольфрама от содержания кобальта.

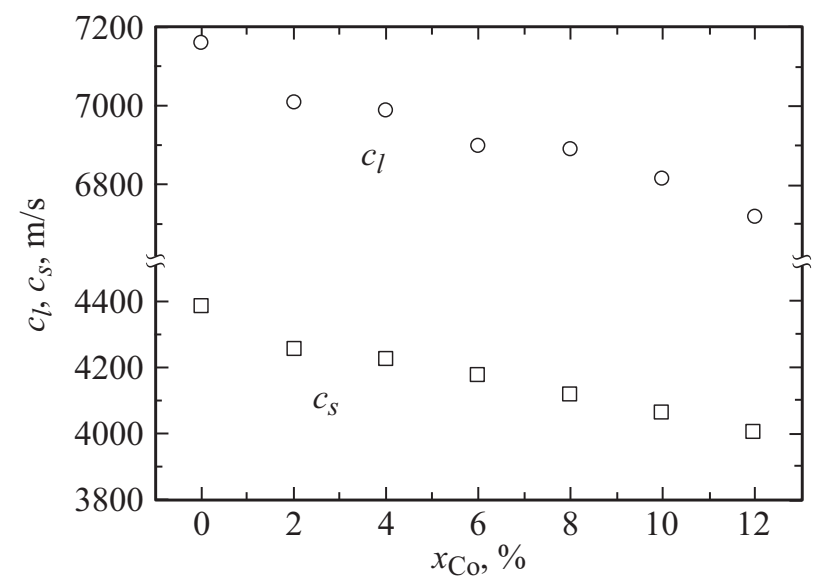

Рис. 4. Зависимости измеренных продольной и сдвиговой скоростей звука образцов карбида вольфрама от концентрации кобальта.

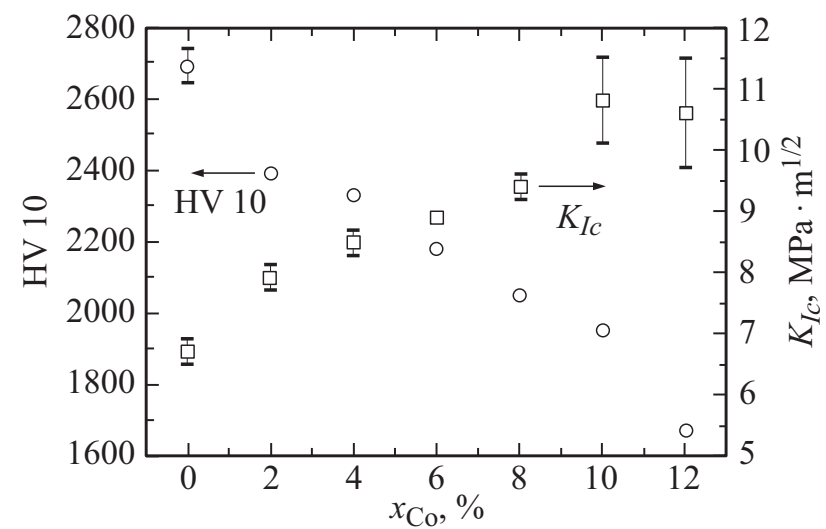

Рис. 5. Твердость и трещиностойкость карбида вольфрама с различным содержанием кобальта.

лась до чистоты $1 \mu \mathrm{m}$, которая затем использовалась для измерения твердости под нагрузкой $98.07 \mathrm{~N}$ в соответствии с процедурой, описанной в [12]. Длина трещин Палмквиста, образовавшихся при вдавливании в керамический образец индентора (алмазной пирамидки) [13], была измерена с помощью оптического микроскопа для определения величины критического коэффициента интенсивности напряжений $K_{I c}$, характеризующего сопротивление материала трещинообразованию. Его величина была рассчитана из уравнения $K_{I c}=0.0028 \cdot\left((H V \cdot F) / \Sigma l_{i}\right)^{0.5}[14]$ по измеренной твердости по Виккерсу $H V$, известной нагрузке $F(98.07 \mathrm{~N})$ и измеренным длинам трещин Палмквиста $l_{i}$. Измеренные значения вышеуказанных параметров представлены в табл. 1 и на рис. $3-5$.

Как видно из табл. 1, средний размер зерна кобальтосодержащей керамики карбида вольфрама составляет около $200 \mathrm{~nm}$ независимо от концентрации кобальта, тогда как в исходном карбиде вольфрама эта величина составляет $\sim 330 \mathrm{~nm}$.

На рис. 3 представлены результаты акустического тестирования образцов, а именно зависимости коэффициента Пуассона, а также модулей Юнга и сдвига от концентрации кобальта в образцах карбида вольфрама. Из рисунка видно, что с ростом количества кобальта 
в исследуемых образцах модуль Юнга уменьшается в соответствии с зависимостью $E=695-11 \times x_{\text {со }}$ от $670 \pm 10 \mathrm{GPa}$ при $2 \%$ Со до $560 \pm 10 \mathrm{GPa}$ при $12 \%$ Сo. Модуль Юнга в чистом карбиде вольфрама составляет $720 \mathrm{GPa}$ и не соответствует расчетному значению из уравнения, представленного выше, так как в этих образцах преобладают ковалентные связи, самые жесткие в этой структуре. Модуль сдвига уменьшается практически линейно в диапазоне от $280 \mathrm{GPa}$ при $2 \%$ Со до $230 \mathrm{GPa}$ при $12 \%$ согласно уравнению $G=290-5 x_{\text {со }}$. Его максимальное значение $300 \mathrm{GPa}$ достигается в образцах карбида вольфрама без кобальта по той же причине, о которой сказано выше для модуля Юнга. Максимальное значение коэффициента Пуассона демонстрируют образцы с содержанием кобальта $10 \%$.

Зависимости измеренных ультразвуковым методом продольной и сдвиговой скоростей звука показаны на рис. 4. С ростом содержания кобальта в образцах карбида вольфрама величины обеих скоростей плавно уменьшаются. Увеличение количества кобальта, в свою очередь, увеличивает количество металлических связей с большими межатомными расстояниями, что и приводит к уменьшению скорости распространения акустических волн.

Влияние содержания кобальта на средние значения измеренной твердости по Виккерсу образцов карбида вольфрама и рассчитанный критический коэффициент трещиностойкости показаны на рис. 5. Исходные образцы карбида вольфрама демонстрируют твердость $2690 \mathrm{HV}$. Наличие кобальта в составе образцов приводит к уменьшению их твердости до $1670 \mathrm{HV}$ при максимальной его концентрации. Критический коэффициент интенсивности напряжений $K_{I c}$, характеризующий сопротивление материала трещинообразованию, наоборот, увеличивается с ростом содержания в карбиде вольфрама кобальта до $10 \%$, рост концентрации кобальта до $12 \%$ немного уменьшает его значение до величины $10.6 \mathrm{MPa} \cdot \mathrm{m}^{1 / 2}$, как это видно из рис. 5.

\section{Прочностные свойства карбида вольфрама при ударно-волновом нагружении}

Проведенные измерения различных параметров изготовленных SPS методом образцов карбида вольфрама с различным содержанием кобальта показали, что во всех случаях наблюдается та или иная их зависимость от концентрации кобальта в образце. С целью изучения влияния содержания кобальта на сопротивление динамическому деформированию и разрушению керамических образцов карбида вольфрама была выполнена серия экспериментов по их ударно-волновому нагружению импульсом сжатия амплитудой $\sim 29 \mathrm{GPa}$. Измерения основаны на регистрации и последующем анализе полных волновых профилей, в частности, профилей скорости свободной поверхности образцов в процессе

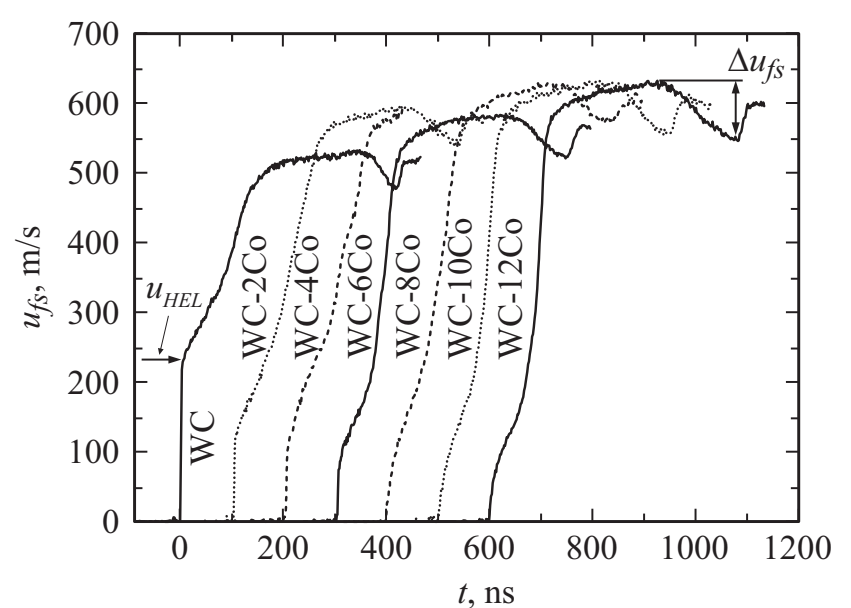

Рис. 6. Профили скорости свободной поверхности образцов керамики карбида вольфрама с различным содержанием кобальта.

нагружения. Суть метода в том, что структура ударных волн и динамика волновых взаимодействий определяются процессами, связанными с изменением сжимаемости вещества в области упругопластического перехода, вследствие полиморфных или фазовых превращений, при образовании дефектов или разрушения в материале и т.д. $[15,16]$. Как правило, при таких измерениях в образцах генерируется импульс одномерного сжатия при соударении плоского образца с плоской пластинойударником, разогнанной каким-либо способом до больших (от сотен метров до нескольких километров в секунду) скоростей. В процессе нагружения проводится регистрация полного волнового профиля, который включает в себя историю нагружения и разгрузки.

Эксперименты по ударно-волновому нагружению проводились на образцах карбида вольфрама с различным содержанием кобальта толщиной 3.8-4 mm. Диаметр образцов составлял $20 \mathrm{~mm}$, что обеспечивало одномерность процесса ударно-волнового нагружения в течение всего времени измерений. Плоские ударные волны в образцах генерировались алюминиевыми пластинамиударниками толщиной $2.0 \mathrm{~mm}$, разогнанными до скорости $1800 \pm 50 \mathrm{~m} / \mathrm{s}$ с помощью взрывных устройств [17]. Образцы размещались на алюминиевых экранах толщиной $2 \mathrm{~mm}$, которые служили для отсечения воздушной ударной волны перед ударником. Во всех экспериментах осуществлялась непрерывная регистрация движения свободной тыльной поверхности образца с помощью лазерного допплеровского измерителя скорости VISAR [18]. Профили скорости свободной поверхности $u_{f s}(t)$ фиксировались с разрешением $1 \mathrm{~ns}$ по времени, точность измерения скорости составляла $\pm 3 \mathrm{~m} / \mathrm{s}$.

На рис. 6 приведены экспериментальные профили скорости свободной поверхности образцов керамики карбида вольфрама с различным содержанием кобальта. На волновых профилях регистрируется выход на поверхность упругопластической волны сжатия и части 
следующей за ней волны разрежения. После отражения импульса сжатия от свободной поверхности внутри образца генерируются растягивающие напряжения, в результате чего инициируется его разрушение - откол. При этом происходит релаксация растягивающих напряжений и формируется волна сжатия (откольный импульс), выход которой на поверхность образца вызывает второй подъем ее скорости. Вследствие вязкого поведения исследуемого материала откольный импульс быстро затухает. Профили скорости свободной поверхности демонстрируют хорошую воспроизводимость при одинаковых условиях нагружения. Увеличение максимальных значений скорости свободной поверхности с увеличением содержания кобальта можно объяснить уменьшением динамической жесткости материала $\rho c^{2}$ и соответственно уменьшением наклона ударной адиабаты. Из табл. 1 видно, что с увеличением содержания кобальта плотность и скорость звука падают.

Напряжение сжатия за фронтом упругого предвестника, соответствующее динамическому пределу упругости (в англоязычной литературе обозначаемому как HEL Hugoniot Elastic Limit), возрастает с уменьшением содержания кобальта и становится максимальным при его отсутствии. Величина динамического предела упругости $\sigma_{\mathrm{HEL}}$ определялась по измеренному профилю скорости свободной поверхности как $\sigma_{\mathrm{HEL}}=\rho_{0} U_{e} u_{\mathrm{HEL}} / 2$, где $u_{\mathrm{HEL}}$ - значение скорости свободной поверхности за фронтом упругого предвестника, $U_{e}-$ скорость упругой ударной волны, которую принимали равной продольной скорости звука $c_{l}$. Отметим, что $\sigma_{\mathrm{HEL}}$, определяемый таким образом, соответствует пределу упругости материала в условиях одноосной деформации. Если выше предела упругости происходит не пластическая деформация, а разрушение, то следует использовать другие соотношения.

На рис. 7 представлена зависимость динамического предела упругости керамики карбида кремния в зави-

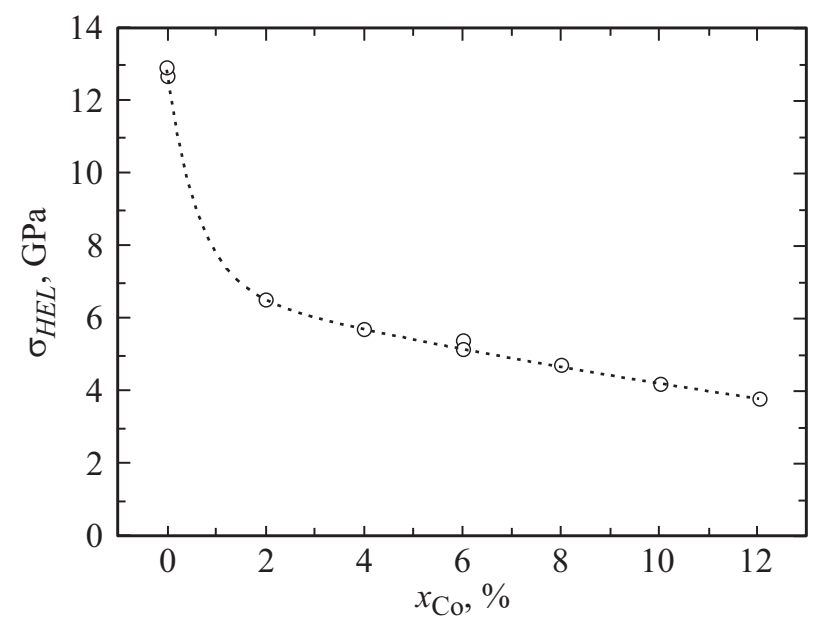

Рис. 7. Зависимость динамического предела упругости керамики карбида вольфрама в зависимости от процентного содержания кобальта.

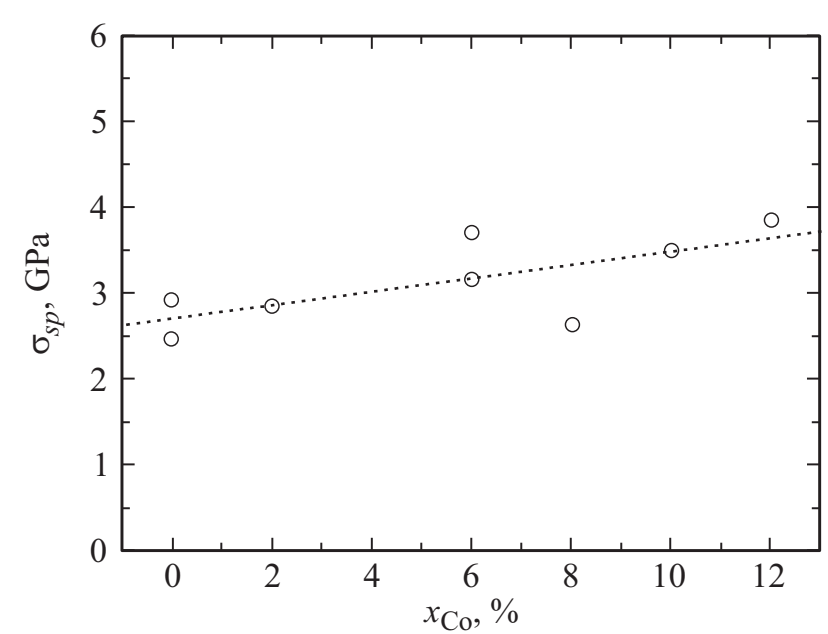

Рис. 8. Зависимость откольной прочности керамики карбида вольфрама от процентного содержания кобальта.

симости от процентного содержания кобальта. Эксперименты демонстрируют хорошую воспроизводимость результатов измерений. Видно, что с увеличением содержания кобальта величина динамического предела упругости линейно уменьшается в диапазоне концентраций кобальта от 2 до 12\% примерно на 40\%. При этом образец без кобальта демонстрирует двукратное увеличение динамического предела упругости по сравнению с образцом, содержащим 2\% кобальта. Такой резкий скачок может быть вызван двумя причинами, каждая из которых могла привести к такому результату в отдельности, либо это результат их совместного влияния. Первая причина - прямое сильное влияние добавки кобальта к чистой керамике. Вторая причина - разница в технологии изготовления образцов, следствием чего является и сильное различие структуры чистых образцов карбида вольфрама и образцов с кобальтом. Напомним, что смесь WC-Co измельчалась, а „чистый“ WC нет, образцы с кобальтом спекались при температуре $1250^{\circ} \mathrm{C}$, а „чистый“ образец - при $1800^{\circ} \mathrm{C}$. Размер зерна спеченных образцов $\mathrm{WC}-$ Со составил $\sim 200 \mathrm{~nm}$, размер зерна „чистого“ образца WC - 330 nm.

Откольная прочность рассчитывалась по измеренной величине $\Delta u_{f s}$ как [19]: $\sigma_{\mathrm{sp}}=\rho_{0} c_{l} \Delta u_{f s} / 2$, где $\Delta u_{f s}-$ спад скорости в регистрируемой волне разрежения перед фронтом откольного импульса, определяемый из волновых профилей, как это показано на рис. 6. На рис. 8 представлена зависимость откольной прочности керамики карбида вольфрама от процентного содержания кобальта. В отличие от динамического предела упругости значения откольной прочности демонстрируют больший разброс значений, что может быть связано с наличием в объеме каждого образца собственных структурных особенностей, таких как разного рода дефекты - микротрещины, микропоры, включения и т. п., которые являются очагами инициирования откольного разрушения. С увеличением содержания кобальта наблюдается ли- 
Таблица 2. Результаты динамических экспериментов

\begin{tabular}{c|c|c|c|c|c}
\hline № & $x_{\mathrm{Co}}, \%$ & $u_{\mathrm{HEL}}, \mathrm{m} / \mathrm{s}$ & $\sigma_{\mathrm{HEL}}, \mathrm{GPa}$ & $\Delta u_{f s}, \mathrm{~m} / \mathrm{s}$ & $\sigma_{\mathrm{sp}}, \mathrm{GPa}$ \\
\hline WC-12Co & 12 & 78.8 & 3.78 & 80.3 & 3.85 \\
WC-10Co & 10 & 85.1 & 4.21 & 70.64 & 3.50 \\
WC-8Co & 8 & 94.2 & 4.73 & 52.6 & 2.64 \\
WC-6Co & 6 & 100.7 & 5.19 & 72.1 & 3.72 \\
WC-6Co-2 & 6 & 97.8 & 5.04 & 61.2 & 3.15 \\
WC-4Co & 4 & 110 & 5.74 & - & - \\
WC-2Co & 2 & 123.3 & 6.52 & 53.8 & 2.85 \\
WC & 0 & 232 & 13.01 & 44.3 & 2.48 \\
WC-2 & 0 & 227 & 12.68 & 52.5 & 2.93
\end{tabular}

нейный рост откольной прочности керамики во всем исследованном диапазоне. В области нулевого содержания кобальта не регистрируется каких-либо особенностей в этой зависимости в отличие от влияния добавки кобальта на величину динамического предела упругости (рис. 7). Результаты расчета прочностных характеристик образцов карбида вольфрама с различным содержанием кобальта представлены также в табл. 2.

\section{Заключение}

Таким образом, проведенные измерения показывают заметное влияние добавок кобальта различной концентрации как на механические характеристики образцов керамики на основе карбида вольфрама, так и на ее прочностные характеристики при ударно-волновом воздействии. Причем эти зависимости могут иметь противоположные тенденции. Показано, что динамический предел упругости исходных образцов карбида кремния примерно в 2 раза превышает его значение при $2 \%$ кобальта в образцах и в 3 раза - при его максимальной концентрации. Откольная прочность карбида вольфрама линейно увеличивается с ростом концентрации кобальта, т. е. наличие кобальта в структуре карбида вольфрама является упрочняющим фактором.

Работа выполнена по проекту гос. задания, № гос. регистрации 0089-2014-0016, и в рамках Программы Президиума РАН № 11П „Теплофизика высоких плотностей энергии“. Авторы также глубоко признательны фонду доктора Э. Крюгера (Германия) за финансовую поддержку этих исследований.

\section{Список литературы}

[1] Buzyurkin A.E., Kraus E.I., Lukyanov Ya.L. // J. Phys.: Conf. Series. 2015. Vol. 653. P. 012036.

[2] McQueen R.G., Marsh S.P., Taylor J.W., Fritz J.N., Carter W.J. // High Velocity Impact Phenomena / Ed. R. Kinslow. NY.: Academic Press, 1970. P. 293-417; appendies on P. 515-568.

[3] Павловский М.Н. // ФТТ. 1970. Т. 12. Вып. 7. С. 2175-2178.

[4] Grady D. // Int. J. Impact Eng. 1999. Vol. 23. P. 307-317.
[5] Appleby-Thomas G.J., Hazell P.J., Stennett C., Cooper G., Helaar K., Diederen A.M. // J. Appl. Phys. 2009. Vol. 105. P. 064916.

[6] Dandekar D.P., Grady D.E. // Shock Compression of Condensed Matter - 2001 / Ed. by Furnish M.D. et. al., AIP CP 620, 2002. P. 783-786.

[7] Amulele G.M., Manghnani M.H., Marriappan S., Xinguo Hong, Fengung Li, Xiomei Qin, Liermann H.P. // J. Appl. Phys. 2008. Vol. 103. P. 113522.

[8] Girlitsky I., Zaretsky E., Kalabukhov S., Dariel M.P., Frage N. // J. Appl. Phys. 2014. Vol. 115. P. 243505.

[9] Guillon O., Gonzalez-Julian J., Dargatz B., Kessel T., Schierning G., Rathel J., Herrmann M. // Advanced Engin. Mater. 2014. Vol. 16. N 7. P. 830-849.

[10] Mandel K., Krüger L., Schimpf C. // International J. Refractory Metals and Hard Materials. 2014. Vol. 42. P. 200-204.

[11] Mandel K., Krüger L., Schimpf C. // Intern. J. of Refractory Metals and Hard Materials. 2014. Vol. 45. P. 153-159.

[12] ISO DIN 3878 Hartmetalle - Vickers-Härteprüfung. Deutsches Institut für Normung e. V, Berlin. 1991.

[13] Булычев С.И., Алехин В.П. Испытание материалов непрерывным вдавливанием индентора. М.: Машиностроение, 1990. $224 \mathrm{c}$.

[14] Schubert W.D., Neumeister H., Kinger G., Lux B. // Intern. J. Refractory Metals and Hard Materials. 1998. Vol. 16. N 2. P. $133-142$.

[15] Зельдович Я.Б., Райзер Ю.П. Физика ударных волн и высокотемпературных гидродинамических явлений. М: Наука, 1966. 688 с.

[16] Kanel G.I., Razorenov S.V., Fortov V.E. Shock-wave phenomena and properties of condensed matter. NY: Springer, 2004. 320 p.

[17] Канель Г.И., Разоренов С.В., Уткин А.В., Фортов В.Е. Ударно-волновые явления в конденсированных средах. М.: Янус-К, 1996. 407 с.

[18] Barker L.M., Hollenbach R.E. // J. Appl. Phys. 1972. Vol. 43. P. 4669-4675.

[19] Kanel G.I. // Int. J. Fract. 2010. Vol. 163. N 1. P. 173-191. 